\title{
BURNOUT IN THE MILITARY
}

\author{
Raluca RUSU \\ rbalasoiu@yahoo.com \\ “NICOLAE BĂLCESCU” LAND FORCES ACADEMY, SIBIU, ROMANIA
}

\begin{abstract}
:
In this paper we will analyze and measure how one of the most common phenomena that causes dysfunctions in organizations burnout - is present among students. In order to achieve this goal, we will study how the three dimensions of burnout, namely: emotional exhaustion, depersonalization and reduction of professional achievement are manifested in the chosen sample.
\end{abstract}

\section{KEYWORDS:}

Organizational pathology, burnout, emotional exhaustion, depersonalization, reduced performance

\section{Introduction}

More and more organizations, especially modern ones, are upset and facing phenomena such as organizational dysfunctions and organizational crises. All these create serious and generalized maladaptive effects that influence not only the organizational performance but also the socio-professional life of the employees. They affect the work capacity of the members of the organization, the formal and informal relations between them, their well-being and above all, the work efficiency. Over time, the organization transforms from a healthy one to one that is unwell and we can talk about phenomena that we bring together under the term organizational pathology. The purpose of this paper is to bring into discuss one of these, namely burnout.

The notion of organizational pathology starts from the idea that just as a healthy organism goes through states of disease, the organizational health can also be affected. In a broad sense, organizational pathology designates the organizational dysfunctions that produce, accentuate and accelerate organizational risks, and in a narrow sense designates neurotic organizational manifestations, which have their origin in the neurotic style of the leader, namely in the pathological characteristics of the dominant group within the organization, especially in the management group, spread throughout the organization (Zlate, 2007).

The first meaning could be illustrated with phenomena such as: burnout, mobbing, workaholism, organizational stress, which acutely affect the climate and organizational performance. In this paper we will focus on the study of how burnout affects individuals and by extension the organization.

\section{Burnout in the military organization}

In the first researches dedicated to this phenomenon, Freudenberger, Richelson, (1980), considers that it is specific only to 
some trades, namely those of assistance or help. He also expressed the opinion according to which the employees, devoted to some causes, are prone to experience burnout. C. Maslach (1982) operationalizes the phenomenon more concretely, presenting it as a symptom of emotional exhaustion, depersonalization and reduction of personal achievement at work due to professional activity.

Thus, the author considers that burnout syndrome is a combination of emotional exhaustion, depersonalization and negative feelings about oneself. Emotional exhaustion is an organism's reaction to stress and is a continuous waste of its own resources. It involves the loss of energy and motivation which leads to the perception of work as a chore (Maslach, 1996). Depersonalization is associated with the emergence of impersonal attitudes, detachment, as a mechanism designed to cope with the depletion of internal resources. Low staff performance refers to negative assessments of personal skills and productivity and involves decreased selfesteem, self-depreciation (Popov, Miljanović, Stojaković \& Matanović, 2013).

Like stress, or perhaps more than stress, burnout causes devastating effects on people's professional lives. People who experience this phenomenon are described as tired, exhausted, with poor health and severely impaired work capacity.

The stressors to which military personnel are subjected can cause some obvious or hidden disorders, especially anxiety, but also the development of burnout syndrome. Long-term stress and frustration caused by the efforts made in daily life, but also conflicts and role ambiguity, promote or exacerbate burnout, indicating that the whole world of a person's life is involved (Balandiz \& Bolu, 2017).

In the military, there are certain categories of personnel among whom the probability of burnout increases. The authors (Balandiz \& Bolu, 2017), talk about the military flight personnel, about those in the area of operational actions and about the medical personnel, especially about the medical staff from intensive care and those from the psychiatry departments. The reality is that all people who aspire to perfectionism have a special tendency to this syndrome, those who have unrealistic expectations about themselves, their job and about leadership. Some conflicts related to professional roles result in emotional exhaustion, an ambivalent attitude towards their workplace, reduced job potential and organizational confidence.

Researchers have tried to establish why the phenomenon of burnout is more likely in some work environments than in others. The professional characteristics examined in terms of the degree of burnout include overwork, role ambiguity, role conflict, lack of control, lack of positive feedback and stressful interpersonal tasks.

\subsection{Overwork}

Burnout is usually caused by intense work over a longer period of time. DePaepe J., French R. and Lavay B. (1985) have shown that teachers who have a larger number of students are more exposed to burnout and, in particular, to emotional exhaustion. In another study conducted by Wilcox V. L., Garrigan J. and Manning F. J. (1992) it was found that burnout has a different result on cadets compared to noncommissioned officers. Among the cadets, the more hours they worked a day, the more emotional exhaustion increased. For noncommissioned officers, several hours worked a day resulted in a stronger sense of personal accomplishment. But still, they reported emotional exhaustion due to lack of free time. The explanation is that non-commissioned officers perceive their tasks as significant, but students do not. Students may find that long hours of instruction are meaningless, which increases the risk of burnout. To avoid this, military leaders must effectively manage time and plan all activities and missions properly. 


\subsection{Role ambiguity}

This work-related factor occurs when a person is confused about his or her responsibilities at work. Burnout can be avoided if the organization makes sure that all employees know the rules and what is expected of them at work (Schwad \& Iwanicki, 1982).

\subsection{Role conflict}

It occurs when employees have to fulfill the obligations of two or more roles at work. For example, military leaders are also responsible for carrying out missions and ensuring the safety of their subordinates (Jackson, Schwab \& Schuler, 1986). Military medical personnel may also have difficulty in adapting to both the provision of medical care and the observance of orders as military personnel. Compared to civilians, military medical personnel who are in a battle situation do not treat the most seriously injured, but those who still have a chance to recover and return to the battlefield.

\subsection{Lack of positive feedback}

If an employee does not receive enough information about his work, feelings of frustration may arise and reduce interest in work tasks, get disconnected and reduce the performance of professional tasks (Pines, Aronson \& Kafry, 1981).

Starting from the reality that all these causes are possible to find in the military environment, in this paper the general objective is to identify the level of burnout among military students and identify differences in the three dimensions of burnout depending on the variables included in the research.

\section{Research methodology}

Starting from this desideratum, the objectives of this study are the following:

- Identifying the level of burnout on the three dimensions - emotional exhaustion, depersonalization and reduction of personal achievements - among military students.

- Comparative analysis of differences in size in terms of variables included in the research, depending on the year of study and gender.

An intentionality sample consisting of 150 military students from the "Nicolae Bălcescu" Land Forces Academy was chosen. To assess the level of burnout, the Maslach Burnout Inventory questionnaire was used (Maslach, Jackson \& Leiter, 1986), built on the three dimensions of burnout: emotional exhaustion, depersonalization and reduction of personal achievements. Each dimension is measured by a variable number of items, in total being 25 items placed on a Likert type scale (very rarely, rarely, occasionally, frequently, very frequently).

\section{Data processing and analysis}

To see what the burnout level is, each dimension of the measurement scale is firstly analyzed.

\subsection{Emotional exhaustion analysis}

To identify the level of burnout, the averages for each dimension were calculated. Below is the table with the average scores at the first level, namely emotional exhaustion. 
Table no. 1

Emotional exhaustion

\begin{tabular}{|c|l|l|}
\hline & \multicolumn{1}{|c|}{ Professional exhaustion items } & \multicolumn{1}{|c|}{$\begin{array}{c}\text { Average } \\
\text { scores }\end{array}$} \\
\hline 1. & Towards the end of the work schedule I feel like a squeezed lemon & 2.44 \\
\hline 2. & I feel tired in the morning when I wake up and have to go to work & 2.58 \\
\hline 3. & I feel full of energy and enthusiasm (R) & 2.3 \\
\hline 4. & I have a state of depression and apathy & 1.54 \\
\hline 5. & I feel at the end of my powers & 1.52 \\
\hline 6. & I want to stay away from everyone and rest & 1.68 \\
\hline 7. & I feel indifferent to the things I was interested in before & 1.87 \\
\hline 8. & I become troubled and tense when I think about my current concerns & 1.78 \\
\hline 9. & I feel emotionally exhausted because of my work. & 1.88 \\
\hline
\end{tabular}

In Table no. 1, which includes the average scores calculated on the entire sample, we can notice that the averages of the items that make up the emotional exhaustion dimension are approximately close, except for items 2, 3 and 4 which have a higher average than the rest. Thus, it is noticed that students sometimes feel tired in the morning, and that after the end of a day they feel exhausted. In the case of the other items, the students responded that they rarely felt their effects.

The analysis shows that the level of emotional exhaustion among students is low. Thus, $82 \%$ suffer from emotional exhaustion very rarely and rarely, not feeling the pressure of daily activities. The remaining $13 \%$ answered that they occasionally suffer from emotional exhaustion and only $5 \%$ as suffering frequently. Compared to years of study, it can be seen that those who suffer most from emotional exhaustion, are first-year students (2.09), this average compared to the measurement scale indicates that they still rarely feel emotional exhaustion. The second year students have the lowest average of exhaustion, of 1.87. At the same time, among third year students, the average is 1.90. But, as it can be seen, the differences are not significant.

Regarding the comparison according to gender, male subjects $(n=97)$ feel more emotional exhaustion, with an average of 1.99 than female subjects $(n=53)$ whose average is 1,90 . These averages relative to the measurement scale indicate that both categories rarely feel the effects of emotional exhaustion.

\subsection{Depersonalization}

In as far as the second dimension, depersonalization, is concerned, as can be seen in Table no. 2, there are no significant differences between the averages of the items that measure it.

Table no. 2

Regarding the depersonalization dimension measurement

\begin{tabular}{|l|l|l|}
\hline & \multicolumn{1}{|c|}{ Depersonalization } & \multicolumn{1}{|c|}{$\begin{array}{c}\text { Average } \\
\text { scores }\end{array}$} \\
\hline 1. & $\begin{array}{l}\text { I communicate with some colleagues as if I were communicating with } \\
\text { some objects }\end{array}$ & 1.75 \\
\hline 2. & Lately I have become tougher in my relationships with colleagues & 1.99 \\
\hline 3. & The people I work with are uninteresting and boring people & 1.79 \\
\hline 4. & Sometimes I don't care what happens to my colleagues & 1.97 \\
\hline 5. & I communicate easily regardless of social status and character of people & 2.21 \\
\hline 6. & Colleagues put the burden of their problems and duties on my shoulders & 1.97 \\
\hline
\end{tabular}


The analysis shows that the majority of students, $78 \%$, consider that they suffer from depersonalization very rarely and rarely. The remaining $21 \%$ answered that they occasionally suffer from depersonalization and only $1 \%$ as suffering very frequently.

This analysis demonstrates that the level of depersonalization among students is low and according to the results they are not distant from the individuals around them, they do not they treat them as objects, and as a result they have no remorse due to their own behaviors. Also, the highest average of depersonalization is registered by the second year students, namely 2.09 , then the third year students with an average of 1.89 and those who rarely suffer from depersonalization are the first year students, with an average of 1.86 .

The explanation is probably related to the activities in which they are involved, in the second year of study they begin to receive more responsibilities and when the study was conducted, first year students were not yet fully familiar with their roles.

\subsection{Reduction of personal achievements}

As it can be seen in Table no. 3 of the averages calculated on the items included in the measurement scale, students consider that they do not suffer from diminished professional achievements, the answers to items 3, 4 and 7 are approximately in the middle of the measurement scale, this meaning that they can find the right solutions in conflict situations, can positively influence the work of others and can create a pleasant atmosphere in the group but not always. Compared to the years of study, we note that the highest average of the item referring to the reduction of personal achievement is recorded by first-year students, namely 1.92 , followed by the second-year students with an average of 1.89 and those who recorded the lowest average in terms of the size in question are third-year students with an average of 1.72 . It can be said that as students reach an upper year of study, the level of reduction of personal achievements becomes lower and lower. Regarding gender differences, there are no significant differences on this aspect.

Table no. 3

Aspects related to the level of the reduction of personal achievements

\begin{tabular}{|c|l|l|}
\hline \multicolumn{1}{|c|}{ Reduction of personal achievements } & $\begin{array}{c}\text { Average } \\
\text { scores }\end{array}$ \\
\hline 1. & I have periods when I feel overwhelmed by the situation & 1.92 \\
\hline 2. & Nothing happens the way I want it to & 1.72 \\
\hline 3. & I can find the right solution in conflict situations & 2.07 \\
\hline 4. & I can positively influence the work of my subordinates and colleagues & 2.05 \\
\hline 5. & I have many plans for the future and I believe they can be achieved & 1.69 \\
\hline 6. & I have professional disappointments & 1.83 \\
\hline 7. & I can easily create a friendly and cooperative atmosphere in a group & 2.03 \\
\hline 8. & I can do many things & 1.95 \\
\hline 9. & I think I will be able to achieve many things in life & 1.71 \\
\hline 10. & I feel like someone who went bankrupt & 1.49 \\
\hline
\end{tabular}

The conclusions of the study highlight the fact that the interviewed subjects show a lower and lower level of burnout as they pass in upper years of study, gaining experience in the military environment and managing to better face the challenges. The general explanation of this is given by the fact that the military 
education system prepares them very well for this environment, and the interventions on the dynamics on this phenomenon are possible but also necessary.

\section{Conclusions}

Also called the disease of the fighter, of the one who initially engages too intensely in his work and who eventually reaches disappointments, led to its conceptualization as a fatality. Combined with the fact that burnout is also attributed to individual vulnerability, they favored its consideration as uncontrollable. Avram and
Cooper (2008) that such an approach is not satisfactory, leaving no room for preventive or corrective intervention in the organizational context. There are several variants of interventions at the level of organizations to manage this syndrome, such as human resources management through appropriate selection and recruitment programs, by providing the necessary organizational support to employees, practicing organizational justice, avoiding workload, role ambiguity and promoting tasks' variety.

\section{REFERENCES}

Avram, E., \& Cooper, C. L. (2008). Psihologie organizaţional-managerială. Iași: Polirom.

Balandiz, H., \& Bolu, A. (2017). Forensic mental health evaluations of military personnel with traumatic life event, in a university hospital in Ankara, Turkey. Journal of Forensic and Legal Medicine, Vol. 51, 51-56.

DePaepe, J., French, R., \& Lavay, B. (1985). Burnout symptoms experienced among special physical educators: A descriptive longitudinal study. Adapted Physical Activity Quarterly, Vol. 3, Issue 2, 189-196.

Freudenberger, H. J., \& Richelson, G. (1980). Burnout: The cost of \& achievement. Garden City, NY: Doubleday.

Jackson, S. E., Schwab, R. L., \& Schuler, R. S. (1986). Toward an understanding of the burnout phenomenon. The Journal of applied psychology, Vol. 71, Issue 4.

Maslach, C. (1982). Burnout: The Cost of Caring. New Jersey: Prentice-Hall.

Maslach, C., Jackson, S. E., \& Leiter, M. P. (1996). MBI: The Maslach Burnout Inventory: Manua. California: Consulting Psychologists Press.

Pines, A. M., Aronson, E., \& Kafry, D. (1981). Burnout: From Tedium to Personal Growth. New York: The Free Press.

Popov, B., Miljanović, M., Stojaković, M., \& Matanović, J. (2013). Work stressors, distress and burnout: the role of coping strategis. Primenjena psihologija, Vol. 6, Issue 4.

Schwad, R. L., \& Iwanicki, E. F. (1982). Perceived role conflict, role ambiguity, and teacher burnout. Educational Administration Quarterly, Vol. 18, Issue 1, 60-74.

Wilcox, V. L., Garrigan, J., \& Manning, F. J. (1992). Levels and predictors of burnout in Army personnel.

Zlate, M. (2007). Tratat de psihologie organizațional-managerială. Vol. 2, Iași: Polirom. 